\title{
Assessment of the influence of FDI on the economic growth of the host country: evidence from Kazakhstan
}

\author{
Dinara Rakhmatullayeva ${ }^{1,}{ }^{*}$, Iliyas Kuliyev ${ }^{1}$, Zhaksylyk Beisenbaiyev ${ }^{1}$, and Talgat Tabeyev ${ }^{1}$ \\ ${ }^{1}$ Al-Farabi Kazakh National University, 050040 Almaty, Republic of Kazakhstan
}

\begin{abstract}
The article examines the impact of FDI inflows on the economic growth of the host country, using the Kazakhstan economy as an example. The authors attempted to assess the impact of FDI using a multiple regression model. As a measure of economic growth, Kazakhstan's GDP data for the period 2000-2017 was used. The simulation results didn't reveal the negative impact of FDI on economic growth, but the analysis revealed that the presence of a positive relationship is not essential for assessing the growth of the national economy.
\end{abstract}

\section{Introduction}

Economic growth and development depend essentially on the country's ability to invest and use its resources efficiently. Although investments in Kazakhstan are financed from various sources, most are still funded by domestic savings. In turn, access to foreign sources of capital also plays a huge role for the economy, not only in Kazakhstan, but also in developing and developed countries. Long-term investment flows, in particular FDI, are important to complement the efforts of developing countries in the field of national development, in particular for building infrastructure, expanding technological capabilities, deepening production ties and increasing overall competitiveness.

It should be understood that investments are a sensitive component of GDP and fluctuate most strongly depending on the phase of the business cycle of the economy. Thus, the "accelerator principle", formulated by P. Samuelson (1948), states that with favorable phases of the economic cycle, the growth of real GDP leads to an increase in real investment, which, in turn, leads to a reciprocal growth in gross output [1]. At the same time, how much the country's gross income will change in response to changes in investment has been a matter of study for many years.

\section{Methods and Data}

In the article authors used general scientific methods, such as analysis and synthesis,

\footnotetext{
* Corresponding author: gulnara.sa@gmail.com
} 
deduction, the logical method. In addition, quantitative methods of analysis were actively used - statistical methods and econometric tools, such as regression analysis, ordinary least squares (OLS), and the Stata software application.

In more detail, the quantitative research method was carried out using secondary data, which cover the time period from 2000 to 2017. For empirical analysis, the authors used multiple linear regression analysis, which allowed us to assess the impact of FDI on the growth of the economy of Kazakhstan. The variables that were used are real GDP as a measure of economic growth, gross inflows of FDI, and inflation rate.

\section{Literature review}

In this article, authors rely on the concept of "Investment Development Path" (IDP) by J. Dunning (1981), since this concept clearly links the level of economic development and the level of FDI in the country and, therefore, indirectly indicate the consequences. This concept puts forward a hypothesis about the relationship between the level of development of a country, determined by the indicator of GDP, GDP per capita or other variables, and its international investment position, which implies a net accumulation of FDI. [2, 3].

The main theoretical studies regarding the impact of FDI on the economic development of the host country can be combined into two groups:

1) the theory of economic modernization (based on neoclassical and endogenous growth theories);

2) the theory of the dependence of the economy from FDI (Fig. 1).

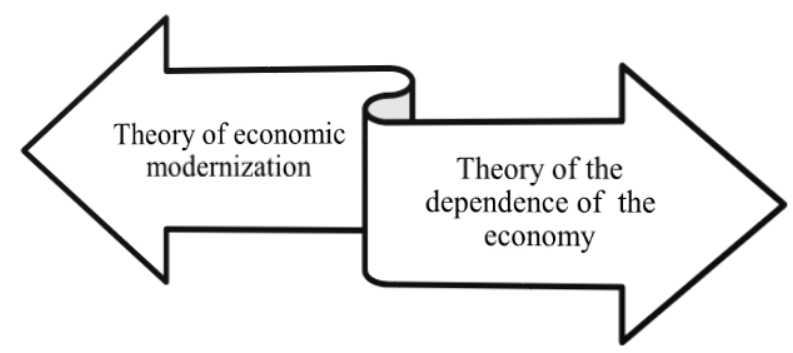

Fig. 1. Types of theories of the impact of FDI on economic development.

Neoclassical theory of economic growth R. Solow (1956) and Rostow (1956) considers FDI as an important growth factor for developing countries [4, 5]. In the Rostow model, FDI is presented as a source of capital and technological transfers to the country necessary for economic transformation. Solow emphasizes the increase in foreign capital and technological progress as important variables in the growth of production and, consequently, development. Theories of endogenous growth explain the positive impact of FDI on the country's economic growth through the expansion of knowledge and the acquisition of new skills by personnel, the introduction of alternative management methods and organizational mechanisms, and, as a result, the rapid spread of technology and increased efficiency of local companies $[6,7,8]$.

In foreign economic literature, the theory of spillover effects (side effects) of FDI in the host country is very common, associated with their function to stimulate economic growth. According to this theory, FDI contributes to the development of four channels of side effects that increase productivity and economic development in recipient countries: imitation, skill acquisition, competition and export. In general, researchers on the theory of modernization, on the one hand, argue that FDI increases income and provides employment opportunities for the host country, thereby stimulating overall economic growth. 
On the other hand, dependency theory researchers argue that transnational companies (TNC) can prevent economic development by crowding out local entrepreneurs, worsening income distribution, reducing consumer welfare, and introducing inappropriate consumption patterns in host countries. It is also worth noting that the favorable impact of FDI is not a specific fact, it may largely depend on favorable conditions in the host country, political and macroeconomic stability, institutional capacity, infrastructure, and education system $[9,10]$.

The most common statement of the theory of dependence is that developing countries "suffer" from the negative consequences of foreign capital in the country due to the repatriation of profits, reduce reinvestment, and increase income inequality. For example, Dixon and Boswell (1996) argued that FDI, although positively affecting economic growth at the very beginning, however, in the long run, the dependence of the national economy on FDI has a negative impact on its growth [11]. Similarly, Moran (1978) investigated that foreign investors adversely affect political processes in the host country; and the benefits of FDI are poorly distributed between TNCs and the host country [12]. In general, supporters of the theory of dependence, for example, Alfaro (2003) and others, blamed TNCs for exploiting developing countries until the $90 \mathrm{~s}$ of the last century and, as a result, the underdevelopment of the "periphery" of the world economy [13]. In support of this, in a study by Kentor et al. (2003) it was proved that countries with a relatively high dependence on foreign capital (measured as accumulated foreign reserves) show slower economic growth than less dependent countries. According to the authors, the concentration of foreign investment has a significant, long-term negative impact on growth, which is the strongest in the first five years and decreases over time [14].

Thus, the empirical literature on the interaction of FDI and economic development was mainly aimed either at measuring the impact of FDI on GDP and productivity growth, or at measuring the determinants of FDI. Most of these empirical studies are cross-country and are based on an analysis of panel data. In general terms, as many researchers in various countries show, in order to achieve the positive effect of FDI, the host country must have an adequate level of human capital, economic stability, and a liberalized capital market. As for studies on the impact of FDI on the economy of Kazakhstan, available studies provide conflicting forecasts regarding the impact of FDI on the national economy. For example, Klaus (2015) in a study of FDI in the CIS studied their effect using data from Kazakhstan [15]. However, his study covered data from 1987 to 1997, when Kazakhstan was one of the republics of the former Soviet Union. Another domestic study was conducted by Rakhmatullayeva et al. (2015), who made an attempt to study the social effects of FDI in the regions of Kazakhstan, and concluded that for the period from 2002 to 2013 investment activity of enterprises with foreign capital didn't adversely effect on the social and economic development of the country's regions [16]. Akhmet-Zaki and Mukhamediyev (2017) investigated the potential determinants of FDI inflows into the region of the Eurasian Economic Union, as a result of which they revealed a significant positive relationship between FDI inflows into the region and GDP, the level of infrastructure and education [17].

In general, authors of this research agree that FDI can have serious consequences, such as growth, export, technology, transfer of know-how, etc. However, these effects vary from country to country and depend on many factors, such as institutional development, human capital development, government policy, the sector, investment motives of TNCs, etc.

Economic development and economic growth are interrelated and interdependent concepts. A positive trend in the country's economic development is the steady growth of the national economy in the long run. International practice shows that an important factor determining economic growth in developing countries exporting mineral resources is the state's investment policy. As a rule, an adequate and reasonable, well-designed investment policy plays a significant role in attracting large flows of FDI to the country. Thus, in developing countries, the relationship between FDI and economic development is clear. By 
economic development, authors mean an increase in the technological level of the economy, an improvement in its sectoral structure and a high standard of living for the population. These issues are especially acute for developing countries that attract FDI, including Kazakhstan. However, it is important to understand that the impact of FDI can be both constructive and destructive. Kazakhstan attracts foreign investors with natural resources and a transit location, respectively; investments come in the extractive and consumer goods and services sectors. And this can have positive consequences for these sectors: improving the level of technology and living standards of the population living in the regions of investment development. However, significant repatriation of profits is one of the main negative consequences of FDI for Kazakhstan.

\section{Results}

Analyzing the relationship between FDI flows and GDP by country, authors found that in 2018, the United States and China were undoubtedly world leaders in both indicators. For example, in the USA, FDI amounted to 354 billion US dollars ( $1^{\text {st }}$ place in the world) and GDP amounted to 20513 billion US dollars ( $1^{\text {st }}$ place in the world). China, as a leading developing country, invested 168 billion US dollars of FDI ( $3^{\text {rd }}$ place) and produced 13457 billion US dollars of GDP ( $2^{\text {nd }}$ place). EU leaders such as Germany, UK and France also show a strong correlation between GDP and FDI: Germany $-5^{\text {th }}$ place in FDI and $4^{\text {th }}$ place in GDP, UK $-7^{\text {th }}$ in FDI and $5^{\text {th }}$ in GDP, France $-9^{\text {th }}$ in FDI and $6^{\text {th }}$ in GDP. The developing economy of Brazil isn't far behind them, which ranks $6^{\text {th }}$ place in FDI and $9^{\text {th }}$ place in GDP $[18,19]$. These countries show good examples of a positive correlation between their FDI flows and their GDP of the country.

The main objective of this research is to study the impact of FDI on Kazakhstan's economic growth. The quantitative research method was applied using secondary data, which cover the dynamics of FDI over the period from 2000 to 2017. The data were obtained from the OECD database [18], and are reliable, according to the authors for the study. The following variables were used for modeling: real GDP of Kazakhstan (Fig. 2), gross inflow of FDI to Kazakhstan and inflation rate.

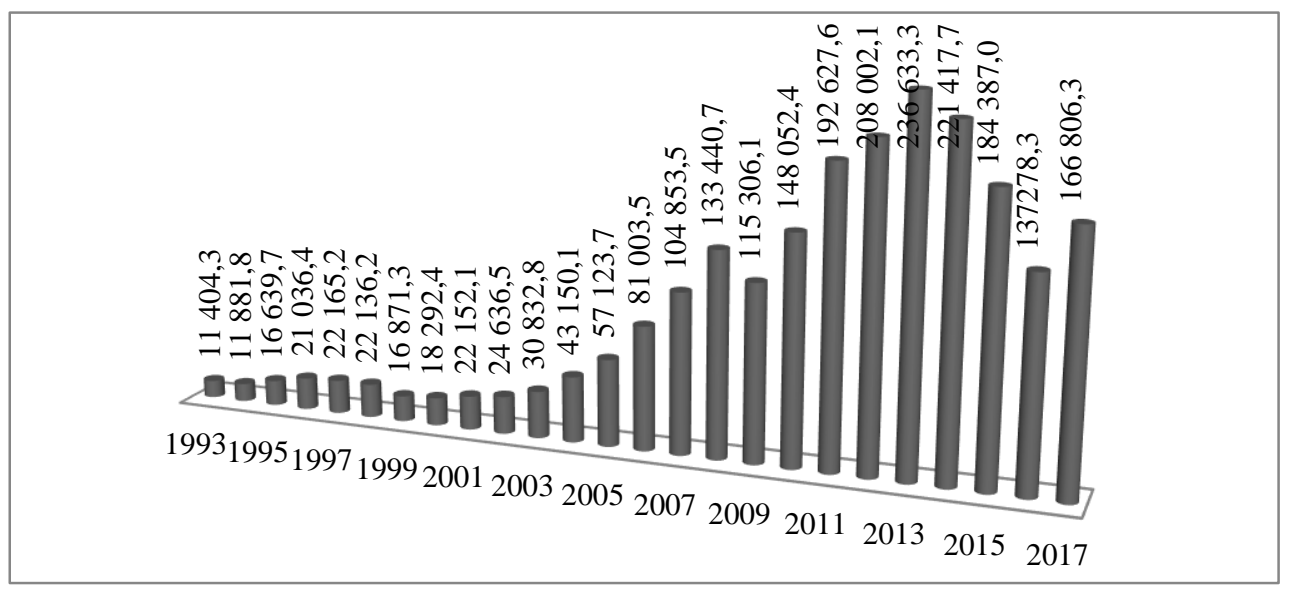

Fig. 2. Dynamics of Kazakhstan's GDP for the period from 1993 to 2017, billion US dollars [20].

According to a research conducted by the authors, the indicator of FDI inflows into the country characterizes the favorable conditions for their functioning in Kazakhstan. However, 
despite this, the inflow of FDI into Kazakhstan has not yet reached pre-crisis levels and continues its "recovery" after the global financial crisis (Fig. 3).

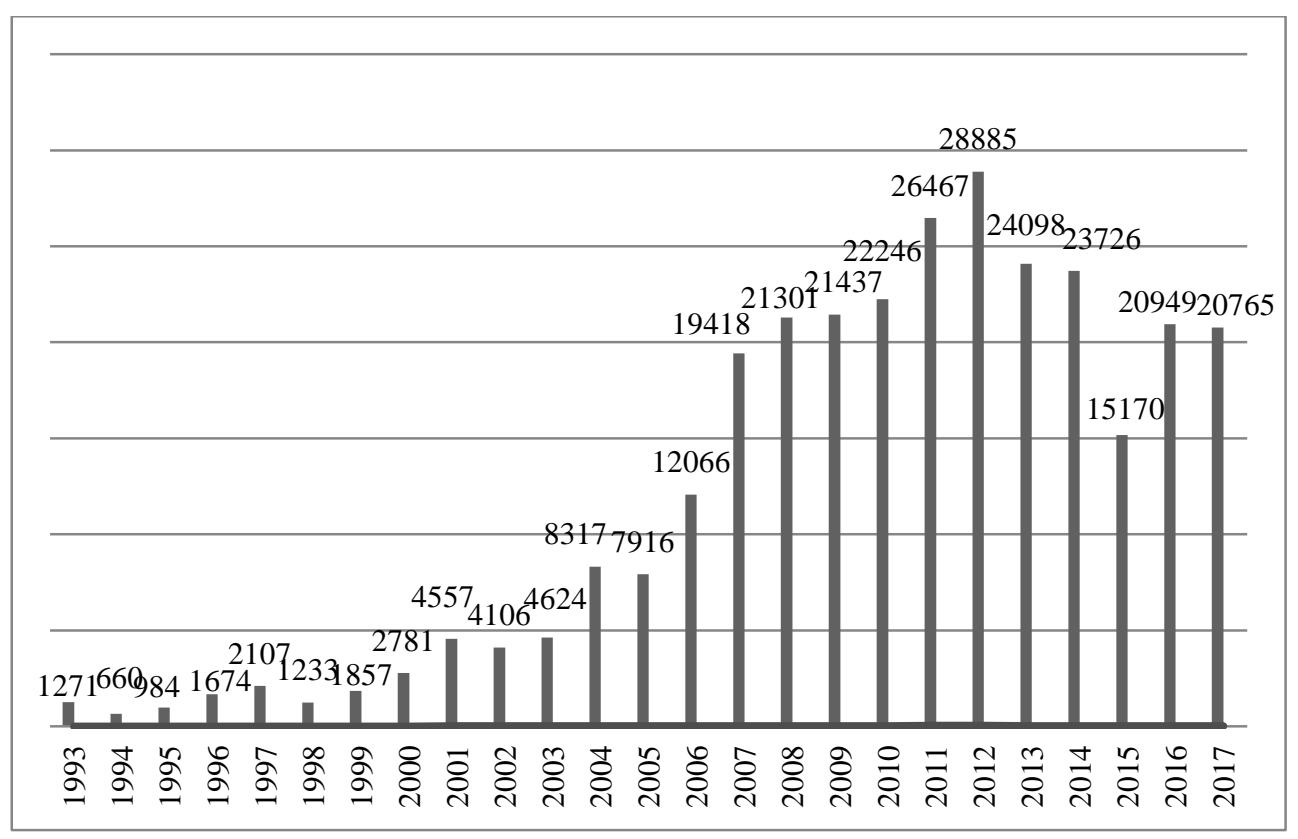

Fig. 3. Gross inflow of FDI into Kazakhstan, 1993-2017 years, billion US dollars [21].

Based on the method of multiple regression analysis, the regression equation in the study is presented in the form:

$$
Y=\beta_{0}+\beta_{1} F D I+\beta_{2} I N F+e
$$

where: $Y$ - real GDP;

$\beta_{0}$ - the intersection of the regression line with the $Y$ axis, denoting the value of $Y$, when the values of $X$ are equal 0 ;

$\beta_{I} F D I$ - FDI inflow to the host country;

$B_{2} I N F$ - inflation rate in Kazakhstan;

$e$ - a variable characterizing a random error.

In the framework of this study, two hypotheses were put forward and tested - the effect or not the influence of FDI inflows on GDP growth in Kazakhstan. When modeling, statistical tests for significance were used. To test the variables at the significance level, a T-test, the Ftest, and the Durbin-Watson test were performed. To check the mutual influence of the variables, a vector inflation matrix was formed, which showed the absence of the multicollinearity problem between the variables included in the equation. To identify the strength of the relationship between the variables, a correlation matrix was compiled. In addition to the tests performed, the variables were checked using the Granger causality test, which can determine which variable changes cause fluctuations in other variables. In given case, is a change in GDP the cause of an increase or decrease in the inflows of FDI into the economy of Kazakhstan, or vice versa, a change in FDI inflows leads to a change in GDP.

Thus, authors attempted to test the main hypothesis of this study to find out if there is any influence of FDI inflows on the economic growth of Kazakhstan. The resulting regression equation for Kazakhstan is as follows: 


$$
L G D P=-25.71+0.12 \cdot L F D I+0.00053 \cdot I N F L A T I O N
$$

LFDI - the logarithm of FDI,

$I N F$ - an inflation rate without a logarithm.

Based on the results of the estimated regression, the determination (2) where: $L G D P$ - the logarithm of GDP, coefficient turned out to be 0.7112 , which means that $71.12 \%$ of the change in GDP of Kazakhstan is explained by FDI and inflation. According to the regression equation above, there's no negative effect of FDI on GDP, however this positive effect is insignificant, the same is observed with inflation. Interpretation of the equation shows that an increase in FDI inflow by $1 \%$ will lead to an increase in GDP by $0.12 \%$, ceteris paribus. As for inflation, an increase of its level by $1 \%$ will lead to an increase in GDP by $0.00053 \%$, provided that the other variables are constant. Accordingly, authors can say that between the inflows of FDI and GDP growth in Kazakhstan, as well as between inflation and GDP there's no significant connection for the period under review. In other words, according to the preliminary results of the model, neither the inflows of FDI into the country, nor the increase in prices have a significant impact on the growth of Kazakhstan's GDP.

Further, authors continued testing hypotheses using the T-test and F-test, to confirm or refute the previously obtained results. The results of the T-test (T-stat) showed that the T-stat for LFDI and INF, which are equal to 0.5268 and 1.4089 , respectively, is lower than the critical value of $\mathrm{T}$ (2.8784) at a significance level of $1 \%$. Thus, the T-test confirmed that the LFDI and INF coefficients are not significant with a confidence of $99 \%$. The F-test also determined that the F-statistic for GDP (14.7789) exceeds the critical tabular value F (5.0919) at a significance level of $1 \%$. This was confirmed by the fact that the coefficients explaining the effects of FDI and inflation aren't zero, and GDP is very high in 99\% significance range. Verification using the Durbin-Watson test revealed ambiguous autocorrelation for GDP for the period under review. Analysis of the correlation matrix showed a weak positive correlation between LGDP and LFDI, while a moderate negative correlation exists between LGDP and INF. Analysis of the vector inflation matrix didn't reveal multicollinearity problems. Finally, authors tested unit roots in order to check whether the variables are constant or not, and also to verify the validity of the resulting regression. This was done in order to prove that the time series doesn't affect the results of the regression, and that the analysis doesn't have the influence of the time factor. As a result, analysis showed that GDP, FDI and inflation are stationary for this model and don't have a single root. Granger's causality test was conducted to determine the causal relationship between the regression variables. The analysis showed that the FDI variable is not the cause of the GDP variable at a $5 \%$ significance level, i.e. in $95 \%$ of cases. Inflation also doesn't cause a change in GDP, and vice versa. However, there is a unidirectional causal relationship and long-term relationships between FDI variables and inflation, which allows the authors to believe that trends in FDI inflows into the country can be used to predict inflation in Kazakhstan.

\section{Conclusion}

In this work, authors study the impact of FDI on the economic growth of Kazakhstan using annual data for the period from 2000 to 2017. Authors came to the following conclusions:

Firstly, as a result of modeling the influence of FDI inflows on GDP growth in Kazakhstan, authors obtained the multiple regression equation, which didn't reveal the negative impact of FDI on economic growth in the country.

Secondly, there is a positive but insignificant relationship between FDI and their impact on Kazakhstan's economic growth. The T-test and F-test confirmed the insignificance of the connection, while all the variables were tested for the absence of autocorrelation between 
them and multicollinearity; it was also proved that there is no causal relationship between FDI and GDP of Kazakhstan. Consequently, the impact of FDI remains unclear, since the study revealed that there was no significant relationship between them. An analysis of theories of the impact of FDI on economic development has shown that FDI generates growth in the country through other sectors of the economy, such as education or research and development. Consequently, the authors' inability to use these variables in this article may have given some limitations to determine the true impact of FDI on economic growth in Kazakhstan.

Thirdly, authors believe that one of the possible reasons for the non-importance of FDI in Kazakhstan may be a problem associated with the lack of technological advances to the country. In this regard, authors for future research recommend including important variables such as R\&D and education level, because, based on the theory of FDI growth, this may be important for determining the role of FDI in the economic growth.

Fourth, authors believe that the inclusion of a larger time series and the most number of variables in the study would provide different results of the influence of FDI on the growth of the national economy. The limitation for modeling was the inaccessibility of data until 1991 , due to the republic gaining independence only this year.

Thus, an analysis of foreign experience has shown that in many developing countries there has been a positive impact on economic growth, however, it is important to remember that this influence is long-term and causes various side effects that may be ambiguous for the host country. Ultimately, it will all depend on how the regulatory authorities for attracting FDI to Kazakhstan follow national interests, how developed the institutional environment and legal support is for the mechanism for attracting and regulating FDI inflows, what is the state of the investment climate in Kazakhstan, the country's position in Doing Business ranking, etc. Nevertheless, the country's government is focused on attracting direct investors to the country and creates all the conditions for this.

\section{References}

1. P. Samuelson, Economics, Vol. 1, 224 (1993)

2. J.H. Dunning, R. Narula, The investment development path revisited: some emerging issues", in John H. Dunning and Rajneesh Narula, eds., Foreign Direct Investment and Governments: Catalysts for Economic Restructuring, 1-41 (1996, e-book 2000).

3. P. Enderwick, Attracting the "Desirable" FDI: theory and evidence, transnational corporation, TC, 14, 93-119 (2005)

4. R. Solow, A Contribution to the Theory of Economic Growth, QJE, 70, 65-94 (1956)

5. W. Rostow, The Take-Off Into Self-Sustained Growth, EJ, 66, 25-48 (1956)

6. E. Borensztein, J. De Gregorio, J.W. Lee, How does foreign direct investment affect economic growth?, JIE, 45, 115- 135 (1998)

7. L.R. De Mello, Foreign direct investment in developing countries and growth: A selective survey, JDS, 34 (1), 1- 34 (1997)

8. L.R. De Mello, Foreign direct investment- led growth: Evidence from time series and panel data, OEP, 51, 133-151 (1999)

9. M.W. Hansen, J. Kuada, Transnational Corporation and Local Firms in Developing Countries: Linkage and Upgrading, CBSP, 29-57 (2006)

10. E. Rugraff, M.W Hansen, Multinational Corporations and Local Firms in Emerging Economies, AUP, 1, 13-47 (2011)

11. W.J. Dixon, T. Boswell, Dependency, disarticulation, and denominator effects: Another look at foreign capital penetration, AJS, 102, 543-562 (1996)

12. T. Moran, Multinational corporations and dependency: A dialogue for dependentistas and non- dependentistas, IO, 32, 79-100 (1978) 
13. L. Alfaro, Foreign Direct Investment and Growth: Does the Sector Matter? HBS, 1-31 (2003)

14. J. Kentor, T. Boswell, Foreign Capital Dependence and Development: A New Direction, ASR, 68, 301-313 (2003)

15. K. Meyer, Foreign Direct Investment in Emerging Economies, IESBS, 10.1016 (2015)

16. D.Zh.,Rakhmatullayeva, V.N. Bobkov, E.B. Zhatkanbayev, Modeling of Social Effect of Foreign Direct Investment in The Regions of Kazakhstan, ER, 2, 285-300 ( 2015)

17. Ye.Zh. Akhmetzaki, B.M. Mukhamediyev, FDI Determinants in the Eurasian Economic Union Countries and Eurasian Economic Integration Effect on FDI Inflows, ER, 13 (3), 959-970 (2017).

18. OECD, FDI flows (indicator). doi: 10.1787 / 99f6e393-en, (2020)

19. OECD, Gross domestic product (GDP) (indicator). doi: 10.1787 / dc2f7aec-en, (2020)

20. MNE RK, SC. URL: https://stat.gov.kz/official/dynamic (2020),

21. NBK, Direct Investments Statistic according to the directional principle, URL: https://nationalbank.kz/?docid=469\&switch=english (2020) 